\title{
Linchamento
}

\section{o lado sombrio da mente conservadora}

\author{
JOSÉ DE SOUZA MARTINS
}

\begin{abstract}
RESUMO: Os numerosos casos de linchamento no Brasil, nos últimos 20 anos, sugerem que as mudanças sociais estão ocorrendo em direção oposta à das orientações cognitivas adotadas pelos cientistas sociais. Os linchamentos indicam que a cultura popular, nas circunstâncias do desenvolvimento e da modernização excludentes, nem sempre é e nem está necessariamente voltada para a a afirmação de tradições que dignificam o homem e afirmam sua emancipação e sua liberdade. Eles revelam sem dúvida uma mentalidade de compromisso com o primado do social e dos direitos da sociedade em relação ao indivíduo. Mas, revelam-no em sua dimensão mais opressiva e punitiva, assumindo formas violentas de exclusão e desumanização ritual de suas vítimas.
\end{abstract}

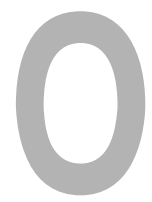

O grande número de linchamentos no Brasil, nos últimos vinte anos, e até a intensificação de sua ocorrência nos anos recentes, nos põe, evidentemente, diante de um problema social. Não porque a sociedade, como supõe a tradição dos estudos de problemas sociais, se inquiete com a disseminada manifestação dessa forma de justiçamento. Mas porque, aos sociólogos, esse tipo de crime coletivo sugere um quadro de mudanças sociais que poderiam ser definidas como patológicas. Pois são mudanças que correlacionam o desenvolvimento e a modernização da sociedade na superfície visível; e, na profundidade invisível e nos recantos escuros de um cenário urbano que se expande deteriorado, a afirmação de valores negativos, que não se inserem no elenco de concepções positivas a respeito da constituição da humanidade do homem: os procedimentos modernos, legais, institucionais e racionais de aplicação da justiça, a liberdade, a responsabilidade, a cidadania. Ao contrário, os linchamentos se baseiam em
UNITERIMOS: linchamentos, vigilantismo, justiça popular, justiça antijudiciária.

Trabalho apresentado no Painel Extra-legal violence in Brazil: Popular Justice, Vigilantism and Lynching, $3^{\text {a }}$ Conferência do Brazilian Studies Association, Cambridge (Reino Unido), 7-10 de setembro de 1996.

Professor do Departamento de Sociologia da FFLCH-USP 
julgamentos freqüentemente súbitos, carregados da emoção do ódio ou do medo, em que os acusadores são quase sempre anônimos, que se sentem dispensados da necessidade de apresentação de provas que fundamentem suas suspeitas, em que a vítima não tem nem tempo nem oportunidade de provar sua inocência. Trata-se de julgamento sem a participação de um terceiro, isento e neutro, o juiz, que julga segundo critérios objetivos e impessoais, segundo a razão e não segundo a paixão. Sobretudo, trata-se de julgamento sem possibilidade de apelação.

Uma história dos linchamentos no Brasil recua até o século XVI, quando essa palavra ainda não existia, pois só surgiria no século XVIII, nos Estados Unidos. Vários episódios de ação coletiva para punir alguém, em espaço aberto, podem ser arrolados em diferentes ocasiões da história brasileira. Eles não têm grandes diferenças formais em relação aos linchamentos dos dias de hoje. O mais antigo de que tenho notícia é o de Antônio Tamandaré, em 1585, em Salvador, Bahia, índio que liderava um movimento messiânico que encontrara grande número de adeptos entre os brancos, inclusive brancos ricos. Os próprios índios seus seguidores queimaram-lhe o templo, prenderam-no, maltrataram-no, cortaram-lhe a língua e o estrangularam (cf. Vainfas, 1995, p. 219 ss.). Um comportamento completamente estranho às tradições tribais e claramente referido a uma cultura punitiva branca, católica e inquisitorial, de acordo com a concepção de castigo e os valores da época. Um caso não muito diferente dos casos atuais de ataque a delegacias para linchar presos. No século XVIII, houve vários linchamentos em Minas Gerais, fundados em sentimentos nativistas, parecidos, na execução, com os de hoje (cf. Boxer, 1969, p. 86 ss.). No final do século XIX, os jornais brasileiros já utilizam essa palavra para designar as ações coletivas de justiçamento.

Entretanto, a comparação das ocorrências de diferentes épocas mostra que os linchamentos entre nós tem sido praticados por motivos que mudam ao longo do tempo. Hoje, de modo algum se lincharia alguém pelos mesmos motivos que justificam linchamentos dos séculos XVI ao XVIII. E, embora os linchamentos do século XIX tivessem clara motivação racial, praticados contra negros ou contra brancos que protegiam negros, os linchamentos de hoje contra negros, ainda que conservando, aparentemente, a motivação racial, têm motivos imediatos completamente diferentes. Naquela época, o negro motivava linchamento quando ultrapassava a barreira da cor e invadia espaços, situações e concepções próprias do estamento branco; quando, enfim, fazia coisas contra o branco que, feitas pelo branco contra o negro, não seriam crime. Hoje, um negro não é linchado por ser negro. Mas, os dados desta pesquisa mostram que a prontidão para linchar um negro é, na maioria dos casos, maior do que para linchar um branco que tenha cometido o mesmo delito.

Se há essa variação na relação entre o motivo e a forma do linchamento, há entretanto uma constante: o que move a multidão à prática do linchamento é a motivação conservadora, a tentativa de impor castigo exem- 
MARTINS, José de Souza. Linchamento, o lado sombrio da mente conservadora. Tempo Social; Rev. Sociol. USP, S. Paulo, 8(2): 11-26, outubro de 1996.

plar e radical a quem tenha, intencionalmente ou não, agido contra valores e normas que sustentam o modo como as relações sociais estão estabelecidas e reconhecidas ou os tenham posto em risco ${ }^{1}$. Há, portanto, dois planos a serem considerados na sua recíproca referência: de um lado, o que estou chamando de mente conservadora; de outro, as ações coletivas violentas que essa mente conservadora informa e justifica. Esses planos se combinam e se explicam reciprocamente.

Penso que se pode estudar os linchamentos como ocorrências documentais que constituem a ponta visível de processos sociais e da estrutura desta sociedade que, de modo geral, têm sido negligenciados pelos estudiosos. Nas últimas décadas, os nossos juristas mais preocupados com as violações dos direitos humanos e os nossos cientistas sociais mais interessados nos eventuais bloqueios à modernização tem dedicado razoável atenção ao que se poderia definir como processos de gestação da cidadania. A referência dessa orientação tem sido, evidentemente, o regime ditatorial recente e recém-encerrado e, a partir dela, a busca, pelos pesquisadores, das evidências de um movimento antagônico orientado em favor da democracia e do direito.

Essa ênfase, no meu modo de ver, distorce a compreensão de ocorrências como as dos linchamentos. Distorce porque todas as ações ilegais, contrárias ao reconhecimento da cidadania do outro, mesmo do criminoso, tendem a ser, de modo reducionista, agrupadas num mesmo e supostamente uniforme conjunto de violações dos direitos do cidadão. Nos debates a respeito dos linchamentos, é possível perceber que muitos confundem a ação dos linchadores com a ação dos chamados justiceiros, apesar da enorme diferença entre as motivações de uns e outros e entre um e outro modo de justiçar. Confundem, portanto, linchamento com vigilantismo ${ }^{2}$. Em decorrência, tendem a supor, com razão ou não, pois isso não vem ao caso neste estudo, que o vigilantismo (e, portanto, também o linchamento) acoberta envolvimento policial e é, por isso, mera extensão de práticas de ação extralegal muito disseminadas no tempo da ditadura militar.

A inferência implícita é a de que, de certo modo, os linchamentos ocorrem porque a polícia é omissa ou, até mesmo, conivente. E são, por isso, expressão de uma orientação política que favorece a prática da justiça extralegal. Como se o Brasil arcaico e totalitário conspirasse ativamente nos meandros do poder para impedir a definitiva e plena constituição do Brasil moderno e democrático. Ou, inversamente, para os que estão no poder, como se o Brasil informal e espontâneo das inquietações de rua conspirasse para impedir a ação iluminista do Estado modernizador. Como se as manifestações de arcaísmo nas diferentes formas de violência não fossem elas próprias engendradas no mesmo processo que engendra a modernização inconclusa e enferma. Como se o próprio desenvolvimento forçado (e a globalização forçada associada à modernização de superfície) não fosse uma violência que instaura e dissemina uma cultura da violência e do medo e promove uma diferenciação social que situa seus distintos produtos em distintos momentos de civilização
Para uma visão de conjunto dos linchamentos no Brasil, cf. José de Souza Martins (1989, p. 21-27).

2 Sobre o vigilantismo, cf. Richard Maxwell Brown, (s.d., p. 154226); W. Eugene Hollon (1974, passim); Peter C. Sederberg (1978, p. 287-305). 
3 Com a devida cautela, que de fato se deve ter no uso dessa concepção, Benevides fala em "linchamentos comunitários" (cf. Benevides, 1982, p. 99). e barbárie, em distintos tempos históricos que se combinam e se anulam reciprocamente.

Minha análise vai em outra direção. Em primeiro lugar porque os dados de minha pesquisa mostram, acima de qualquer dúvida, que os linchamentos diferem profundamente do que a própria imprensa classifica como chacinas, praticadas por justiceiros ou, mesmo, policiais. O linchamento tem caráter espontâneo e o típico linchamento se configura em decisão súbita, difusa, irresponsável e irracional da multidão. Mesmo nos casos em que o linchamento não é praticado pela típica multidão anônima e o é por grupos mais bem "comunitários", não decorre de uma atitude de vigilância para reprimir o crime, como é próprio do vigilantismo.

No caso brasileiro, há uma razoável gradação de diferenças em relação a esse modelo de conduta de multidões, como também há na história de linchamentos em outros países. Ainda assim, os linchamentos decorrem, na maioria dos casos, do elemento qualitativamente novo constituído pela reunião ocasional de grande número de pessoas e a conseqüente formação da multidão. Esta age como se fosse uma espécie de segunda e coletiva personalidade dos indivíduos, como sugere Le Bon (1977). É como se o indivíduo e sua razão fossem engolfados e dominados pela vontade coletiva e irracional da massa atuando em conjunto em função de objetivos propostos casualmente pelas circunstâncias. Os materiais que colhi oferecem muitas evidências nesse sentido. Já as chacinas são praticadas intencionalmente, não raro mediante pagamento, por grupos muito pequenos e, quando se trata de justiceiro, por uma única pessoa. É evidente que, tanto no caso de linchamentos quanto no caso de chacinas, estamos em face de pessoas que praticam a justiça pelas próprias mãos. Mas, há substanciais diferenças entre as motivações e as formas de execução da pena arbitrária, tanto num caso quanto noutro.

Ao colocarem grande ênfase nas orientações positivas dos agentes da luta pela cidadania, os cientistas sociais deram preferência ao estudo dos movimentos sociais, movimentos orientados por objetivos sociais evidentes e modernizadores isto é, de algum modo politizados. Entretanto, simultaneamente à proliferação dos movimentos sociais, a partir dos anos 70, estavam transcorrendo ações que os sociólogos mais antigos chamavam de comportamento coletivo (cf. Blumer, 1962, p. 209-272): os quebra-quebras de ônibus, de trens, de estações ferroviárias, os saques e os linchamentos. E, nesses casos, não só a conduta em si mesma se desenrolava e desenrola predominantemente de modo irracional e emocional, como sua orientação é egoísta e anti-social, ainda que praticada em nome de valores sociais relativos à manutenção da ordem e à preservação do interesse de todos, como, aliás, ocorre nos linchamentos.

Com isso, toco num outro ponto problemático que nos leva justamente ao problema sociológico desta pesquisa. Ainda que sem precisão alguma, os estudiosos desses movimentos, no período recente, tenderam a 
MARTINS, José de Souza. Linchamento, o lado sombrio da mente conservadora. Tempo Social; Rev. Sociol. USP, S. Paulo, 8(2): 11-26, outubro de 1996.

supor que o comportamento coletivo constituía como que o preâmbulo dos movimentos sociais e dos movimentos propriamente políticos ${ }^{4}$. Uma certa tolerância romântica implícita em relação a formas de delinqüência dos pobres contra os ricos ou do povo contra o Estado, que pareciam sugerir o germe da insurgência revolucionária, marcou de algum modo muitas interpretações dessas ações nos últimos anos. É possível que o descontentamento social no ambiente de repressão política que então prevaleceu tenha encontrado em formas de comportamento coletivo, como as indicadas, um meio de expressão. No entanto, a repressão política foi atenuada e de fato cessou com o retorno do país ao Estado de Direito e a restituição do Estado ao controle de governos civis investidos de mandatos legítimos. As formas irracionais do descontentamento, porém, não só continuaram, como se multiplicaram, especialmente os linchamentos. Um novo quadro social e político de possibilidades de expressão da insatisfação popular não a absorveu nem lhe deu direção e sentido. O que indica, portanto, que o comportamento coletivo não se desdobra necessariamente nos movimentos sociais nem neles se transforma. Ao contrário, ele tende a se constituir e a se manifestar como tendência oposta à destes últimos. Ele expressa como que a dimensão irredutível de uma conduta humana autodefensiva que até mesmo conflita com as conquistas da civilização. Nele, o contrato social não se recompõe e se rompe mais ainda do que na ruptura provocada pela violência primeira que lhe deu origem.

A inviabilidade da transição do comportamento coletivo para os movimentos sociais talvez se deva, ao menos em parte, à ampla desmoralização das instituições, especialmente a Justiça e a Polícia, durante a ditadura. O governo militar interferiu ativamente nelas para torná-las parciais e submetêlas às suas diretrizes políticas. A supressão de certos privilégios dos magistrados e funcionários, que asseguravam a estabilidade necessária à ação judicial isenta, e a aplicação de leis de exceção aos que não decidiam segundo os valores do regime, cassando-os e afastando-os do serviço público, certamente contribuíram para essa desmoralização. E certamente contribuiu no mesmo sentido a transformação das polícias em forças auxiliares da repressão política, deixando em plano secundário a ação policial voltada para a manutenção da ordem social e dos direitos do cidadão. Nos linchamentos é possível "ler" a interpretação prática, para o homem comum, de que as instituições não retornaram ao seu leito natural, que é o do serviço ao cidadão e não prioritariamente ao próprio Estado. A função da polícia, sabemos todos, não é a de prestar um serviço a si mesma, como em grande parte acontecia durante a ditadura.

Os dados utilizados nesta pesquisa, como ocorre em pesquisas realizadas em outros países, especialmente nos Estados Unidos, procedem do noticiário dos jornais ${ }^{5}$. É a única fonte minimamente sistemática disponível em escala nacional. Não há outra. Nem mesmo os registros policiais servem para o estudo dos linchamentos, delitos freqüentemente registrados como
${ }^{4} \mathrm{Na}$ congérie de conflitividades que marcou o período mais repressivo da ditadura, nos anos 70, era compreensível a dificuldade para distinguir o lugar social e histórico (e os alvos) das diferentes formas de ação coletiva da população, especialmente da população urbana. É o que, no meu modo de ver, explica a hipótese de trabalho de alguns estudos sobre movimentos sociais, aliás bem feitos e sugestivos, estudos esses orientados para a busca das referências estruturais e de classe das explosões urbanas. Cf., por exemplo, José Álvaro Moisés e Verena Matinez-Alier (1977, p. 13-63); Edison Nunes (1982, p. 93) e José Álvaro Moisés (1982, p. 51-52).

A dependência dos estudiosos do tema em relação ao noticiário dos jornais, nos Estados Unidos, tem motivado estudos sobre a confiabilidade e a abrangência dessa fonte de informação. Infelizmente, apesar da importância documental crescente do noticiário jornalístico 
MARTINS, José de Souza. Linchamento, o lado sombrio da mente conservadora. Tempo Social; Rev. Sociol. USP, S. Paulo, 8(2): 11-26, outubro de 1996.

nos estudos sociológicos no Brasil, ainda não dispomos de avaliações do mesmo tipo. Esses estudos são úteis sobretudo para determinar as limitações e deformações do dado jornalístico sobre linchamentos. Cf. Warren Breed (1958, p. 291298); David Snyder e William R. Kelly (1977, p. 105-123); Maurine Beasley (1982, p. 8691) e Jill Goetz (1987, p. 60).

${ }^{6}$ Os dados mostram que os linchamentos se enquadram no que Foucault designa como ato de justiça popular profundamente antijudiciário. Cf. Foucault (1982, p. 43). Cerca de 90,0\% das vítimas de tentativas de linchamento foram salvas, em grande número de casos com ferimentos. As polícias militares e civis foram responsáveis por $76,7 \%$ dos salvamentos. homicídios ou tentativas de homicídio. A partir de 1995 pude fazer um rastreamento mais abrangente das notícias de linchamentos e tentativas de linchamento por meio de um serviço especializado em recortes de jornais de todo o Brasil. As tendências verificadas desde então não alteram substancialmente o que já havia sido observado nos vinte anos anteriores, embora haja mais riqueza de detalhes, sobretudo para o estudo de certos aspectos dos linchamentos, como o da sua dimensão ritual. Obviamente, nem todos os linchamentos e tentativas apareceram no noticiário dos jornais a que tive acesso, especialmente as ocorrências no meio rural. Algumas destas últimas chegaram ao meu conhecimento através de pequenos jornais e boletins de igrejas do interior do país e servem basicamente para indicar que a coleção de casos que arrolei está viesada em direção às ocorrências urbanas. Como, no geral, as características dos linchamentos se repetem nas diferentes situações, inclusive se repetem as características peculiares dos diferentes tipos de localidades (áreas metropolitanas, áreas urbanas não metropolitanas e áreas rurais), penso que o elenco de casos dá indicações razoavelmente seguras dos perfis dos linchados e dos linchadores e dos modos e motivos das execuções.

Neste texto me limito à análise dos dados que permitem verificar em que medida o linchamento é um ato de justiça popular antijudiciário 6 .E, por isso, em que medida é uma forma implícita e difusa de contestação das instituições responsáveis pela polícia e pela justiça, elaborada predominantemente a partir de um comunitarismo, em parte real, fundado no parentesco e na vizinhança, e em parte fictício, fundado no medo de vizinhos e moradores. Dados que permitem verificar, também, em que medida o linchamento contém, por tudo isso, uma crítica social conservadora e politicamente inócua às instituições, às pessoas e às tendências de mudança da sociedade. Sobretudo porque a mudança social vista através de uma sociabilidade gestada pelo medo não aparece como resultado do aperfeiçoamento progressivo dos mecanismos de integração social, mas sim como desagregação social. É o que, no meu modo de ver, explica a expressão e a contrapartida formais desse processo no caráter ritual dos linchamentos.

A principal revelação dos dados desta pesquisa é, justamente, a de que essa prática de justiçamento popular não se define pela imagem que dela se tem. No caso brasileiro, os linchamentos de modo algum podem ser explicados exclusivamente por sua redução ao modelo geral de conduta da ação de massa mencionado antes. Eles não são, predominantemente, o resultado da ação de grupos indefinidos e ocasionais, como a multidão espontânea. Analisando conjuntamente os 677 casos de linchamentos consumados e tentativas de linchamento geralmente interrompidas pela ação da polícia ${ }^{7}$, ocorridos nos últimos vinte anos, descobre-se neles quatro categorias principais e bem distintas de linchadores: A - Parentes e amigos de alguém que tenha sido vítima do linchado (8,4\% das ocorrências, $4,3 \%$ dos participantes e 7,9\% das vítimas; grupo médio de 199 linchadores); B - Vizinhos e moradores da localidade de moradia de alguém que tenha sido vítima do linchado 
MARTINS, José de Souza. Linchamento, o lado sombrio da mente conservadora. Tempo Social; Rev. Sociol. USP, S. Paulo, 8(2): 11-26, outubro de 1996.

(44,8\% das ocorrências, 71,4\% dos participantes e 43,8\% das vítimas; grupo médio de 626 linchadores); C - Grupos corporativos de trabalhadores, especialmente motoristas de táxi e trabalhadores da mesma empresa em que trabalha(va) alguém vitimado pelo linchado (12,4\% das ocorrências, $6,0 \%$ dos participantes e 21,4\% das vítimas; grupo médio de 191 linchadores); D Grupos ocasionais, especialmente multidões da rua, transeuntes, passageiros de trens e de ônibus, torcedores de futebol (20,8\% das ocorrências, 16,6\% dos participantes e 19,3\% das vítimas; grupo médio de 312 linchadores) ${ }^{8}$.

Os dados sugerem que se esclareça, desde logo, que a palavra multidão, nos materiais deste estudo, não significa grandes massas agindo numa única direção. Apenas 10,2\% dos casos arrolados referem-se a linchamentos com mais de mil participantes, 54,8\% referem-se a menos de cem participantes e $38,7 \%$ a menos de cinqüenta. A tendência é, portanto, de linchamentos praticados por grupos relativamente pequenos. O que estou classificando como multidão está presente em apenas um quinto do total de linchamentos. E nessa categoria, apenas $6,3 \%$ dos linchamentos tiveram mais de mil participantes. Enquanto isso, 17,3\% dos linchamentos da categoria B, a dos vizinhos e moradores, envolveram mais de mil participantes. Isso é muito mais do que aquilo que estou chamando de multidão. Essas grandes aglomerações, no entanto, diferem do que neste texto é multidão porque são formadas por pessoas que não têm entre si propriamente um vínculo ocasional, anônimo e aberto. Ao contrário do que Canetti define como multidão natural e aberta (cf. Canetti, 1973, p. 17), esses agrupamentos poderiam ser definidos como multidões fechadas, localistas e corporativas, geralmente hostis aos estranhos, entre os quais, aliás, encontram vítimas para os linchamentos que praticam. Os linchadores vivem na mesma localidade e, de certo modo, são vizinhos, ainda que vizinhos distantes. Seu dia a dia envolve grande probabilidade de reencontro, se é que não são "conhecidos de vista”. A recusa de testemunhar e de identificar pessoas nos inquéritos policiais que são instaurados indicam, justamente, mais do que medo de represália, uma consciência de pertencimento e de conivência.

A verdadeira multidão o é menos pelo número dos que a compõem do que pelas características de sua mobilização e participação nos atos de linchar. Neste caso, maciças mobilizações para linchar por grupos que se identificam e são identificados como vizinhos e moradores, não configuram propriamente situações de multidão, embora os comportamentos aí se confundam com comportamentos de multidão. Sobretudo porque a multidão reúne pessoas que não têm entre si outro vínculo que não seja o vínculo ocasional, fortuito e acidental derivado de ação orientada por um objetivo passageiro, embora compartilhado através de um fugaz sentimento de identificação e companheirismo, uma espécie de comunidade breve e transitória9

Meus argumentos se apoiam justamente na constatação de que $80 \%$ dos linchamentos são praticados por agrupamentos de pessoas que se unem para linchar por motivos e relacionamentos de tipo tradicional, comunitário e
8 Os cálculos foram feitos sobre um total de 677 linchamentos e tentativas de linchamento e 952 vítimas, entre mortos, feridos e evadidos.

9 Canetti destaca que é apenas na multidão que o homem se livra do medo de ser tocado (cf. Canetti (1973, p. 16). Essa é uma característica de situações familísticas e comunitárias. 
autodefensivo, grupos com alguma estabilidade e continuidade. Isso contraria o principal pressuposto de que os linchamentos expressam a típica violência da multidão urbana e anônima, que se dispersa em seguida e, provavelmente, não mais se encontra. Os linchamentos ocorridos no Brasil sugerem uma variação interpretativa no estudo desse tipo de violência coletiva. No próprio ato de linchar, o modo como se dá o ajuntamento dos linchadores e a formação da multidão, a sucessão dos momentos fragmentários a partir do instante em que se define um quadro de linchamento iminente até a sua consumação, os instrumentos e gestos empregados no justiçamento, enfim, o instante do linchamento é em tudo igual nos diferentes tipos de grupos de linchamento e é em tudo igual ao modelo do comportamento irracional da massa. Mas, uma coisa é o ato de linchar, cuja significação sociológica nele não se esgota. E outra coisa é a extração social dos linchadores e os vínculos sociais que mantêm entre si fora da situação social do linchamento. Esta pesquisa revela que estamos em face de uma duplicidade sociológica dos linchadores: a imediata e súbita, típica da multidão, e, por trás dela, a estável sociabilidade da vizinhança e do bairro, típica da comunidade.

Por isso, apesar dessas características tradicionalistas da maioria dos grupos envolvidos, $61,1 \%$ dos linchamentos registrados ocorrem nas regiões metropolitanas, $29,8 \%$ em cidades não situadas em regiões metropolitanas e apenas $0,7 \%$ nas zonas rurais. Os linchamentos que podem ser estudados no Brasil constituem um fenômeno caracteristicamente urbano, que se dá num ambiente caracteristicamente anti-tradicionalista. Tentei estabelecer uma escala de gradação do mais caracteristicamente tradicional e menos urbano ao mais caracteristicamente moderno e mais urbano em relação aos membros dos grupos de linchamento para melhor compreendê-los nessa perspectiva. No primeiro extremo estão os grupos formados por parentes e amigos das vítimas dos linchados (A). No segundo extremo estão os grupos que constituem o que estou classificando como multidão (D). Entre os dois pólos estão, nesta ordem, os grupos de linchamento formados por moradores e vizinhos (B), que é o grupo mais numeroso, e, em seguida, os grupos formados por membros da mesma profissão ou da mesma empresa (C).

Distribuindo-se as ocorrências pelas regiões geográficas do país, observa-se que $14,0 \%$ dos linchamentos praticados pelo grupo A estão na região norte, uma região de fraca urbanização, enquanto a participação desse grupo no conjunto do país é de $8,4 \%$. No outro extremo, 4,3\% dos linchamentos por multidão (grupo D), ocorreram naquela região, enquanto a participação desse grupo no país é de 20,8\%. Há aí, portanto, a indicação de uma tendência a confirmar as raízes tradicionalistas dos linchamentos praticados pelo grupo A. No outro pólo, $77,3 \%$ dos linchamentos executados pelo grupo D (multidões) ocorreram no Sudeste, uma região intensamente urbanizada. No entanto, essa tendência é muito geral, pois, foi no Sudeste que ocorreram 52,6\% dos linchamentos praticados pelo grupo A (parentes e amigos). Isso parece indicar que os padrões tradicionalistas de justiçamento ganham vida e 
MARTINS, José de Souza. Linchamento, o lado sombrio da mente conservadora. Tempo Social; Rev. Sociol. USP, S. Paulo, 8(2): 11-26, outubro de 1996.

encorpam-se nas áreas supostamente mais urbanizadas.

Assinalo, no entanto, que essa prática de justiça popular não é própria nem típica do mundo rural, onde ainda operam sólidos mecanismos de solidariedade familiar e comunal. O que lhe é próprio e típico, e potencial portanto, é a concepção de justiçamento com base no direito de vingança, especialmente nos crimes de sangue ${ }^{10}$. No entanto, uma concepção reformulada e "socializada" de vingança se difunde nas cidades. A raiz, sem dúvida, é rural, comunitária e patriarcal. Mas, na cidade, a vingança por crimes de sangue não tem uma base real e própria, como é o caso das famílias extensas no campo. Essa modalidade de justiçamento persiste e se redefine com base no que sobrevive do mundo tradicional e agrário naquilo que se poderia chamar de sentimento de pertencimento a um grupo, uma certa concepção do "nós", muito diversa da típica sociabilidade urbana. Vizinhos e conhecidos, especialmente nos bairros pobres e de baixa classe média, suprem em alguns momentos e circunstâncias a carência de uma comunidade real, como são as nossas comunidades rurais, quase sempre atravessadas por relações de parentesco real ou simbólico. A base real dessa ação conjunta não é a comunidade de parentesco, mas a comunidade altamente instável gestada pelo medo.

Um linchamento ocorrido em fevereiro de 1996 em Campos, no Rio de Janeiro, é bem indicativo dos valores envolvidos nesses casos. Um adolescente negro matou, para roubar, uma adolescente negra no momento em que esta abria a porta do modesto estabelecimento comercial da família, logo de manhã. Em seguida fugiu e escondeu-se num terreno baldio das proximidades. Mas, o crime fora presenciado por um irmão da vítima, de 4 anos de idade, que identificou o criminoso, pois era conhecido. A população da cidade ajudou a família a procurá-lo, localizou-o, agarrou-o, acorrentou-o a um poste e o entregou à família da moça para linchá-lo. A polícia chegou no momento em que jogavam álcool sobre ele para queimá-lo vivo. Jornais de diversas regiões do país publicaram fotos do linchamento. Nelas se vê os familiares, especialmente a mãe da menina, espancando o criminoso, cercados pela multidão que o aprisionara e que apenas contempla. Pessoas presentes, que ajudaram na captura, recuaram para que a própria família da moça pudesse linchá-lo (O Dia, 1996; Diário Popular, 1996). Um rito de vingança, que o sugere como reconhecimento pela comunidade de um direito preferencial de quem foi violentamente privado de um membro da família. É sobretudo emblemático que os circunstantes dessem precedência de espancamento à mãe da menina, para isso retirada do velório que se realizava ali perto. Esse linchamento, como vários outros, tem algumas características do que em certas culturas pode ser definido como canibalismo simbólico.

Nos dois primeiros grupos de linchamento (A e B), o dos parentes e amigos e também os dos moradores e vizinhos, o móvel dessa prática é freqüentemente referido à vingança. Vingança que se situa num complexo quadro ritual, muitas vezes narrado com detalhes no noticiário da imprensa. Nos outros dois grupos, o móvel do linchamento tende a ser o castigo,
${ }^{10} \mathrm{O}$ dever, o encargo e a responsabilidade da vingança permanecem muito fortes em algumas regiões, sobretudo rurais, como observou Andrade, no sertão do Maranhão entre crianças filhas de pais assassinados, por isso mesmo, também elas sob risco de morte (cf. Maristela Andrade, 1991, p. 37-50). 
especialmente quando praticado por quem não tem de que se vingar.

Em 19,6\% do total de casos de linchamento há indicações claras de que eles se deram sob a forma de ritos sacrificiais, como esse que acabo de descrever. Todos os sinais de ritos que pude colher sugerem que a prática da vingança se ligou a rituais de purificação, rituais através dos quais a comunidade se purga do crime, especialmente do crime de sangue. O que sugere que os linchadores agem em nome do que supõem ser uma comunidade, que vinga, pune e exclui, assim como acolhe. Em 6,9\% dos casos, os linchados foram queimados, quase sempre ainda vivos (um dos casos, aliás, o de Matupá, Mato Grosso, exibido pela televisão); em 6,5\%, foram mutilados; em 0,7\% foram castrados vivos; em 1,0\% foram esquartejados; em 4,9\%, os corpos foram arrastados pelas ruas da localidade de ocorrência; em $4,4 \%$ foram mortos com instrumentos de trabalho dos parentes e amigos das vítimas; em 3,7\%, os corpos foram jogados no lixo ou ficaram expostos em monturos durante muitas horas e até vários dias antes que a polícia fosse avisada. Desse modo podiam ser longamente contemplados pela multidão silenciosa. Em diversos casos de exposição desse tipo, há uma dimensão ritual que se manifesta no empenho em assegurar que a comunidade das vítimas possa testemunhar a putrefação do corpo, recoberto de moscas, possuído lentamente pela morte, transfigurando-se de pessoa em cadáver. Em pelo menos um caso, o criminoso foi apanhado e levado ao velório de sua vítima para que a beijasse antes de ser morto. A ocorrência de vários casos de linchamento, mutilação e arrastamento pelas ruas de cadáveres de pessoas que os grupos queriam linchar, mas que foram mortos de outro modo, geralmente pela polícia, reforça a indicação de que o propósito dos linchadores é mais do que matar sua vítima. É, também, mais do que castigar e exibir publicamente o castigo. Trata-se de impor ao criminoso expiação e suplício reais ou, no caso do que já está morto, expiação e suplício simbólicos, como é próprio dos ritos de vingança e sacrifício. E, além disso, eliminá-lo simbolicamente como pessoa.

Essas práticas indicam que estamos em face de rituais de exclusão ou desincorporação e dessocialização de pessoas que, pelo crime cometido, revelaram-se incompatíveis com o gênero humano, como se tivessem exposto, por meio dele, que nelas prevalece a condição de não-humanas. As mutilações e queimas de corpos praticadas nesses casos são desfigurações que reduzem o corpo da vítima a um corpo destituído de características propriamente humanas. São, portanto, rituais de desumanização daqueles cuja conduta é socialmente imprópria.

Os diferentes casos de linchamentos de presos por outros presos constituem uma expressão extrema dessa concepção. Esses linchamentos atingem de maneira particularmente intensa os estupradores de crianças e mais gravemente quem tenha estuprado a própria filha. Os próprios criminosos parecem sentir-se compelidos a traçar uma linha de sangue que separe humanos de não-humanos para que, forçados a habitar a mesma cela dos que tenham cometido esses crimes, não sejam por sua vez contaminados pela 
MARTINS, José de Souza. Linchamento, o lado sombrio da mente conservadora. Tempo Social; Rev. Sociol. USP, S. Paulo, 8(2): 11-26, outubro de 1996.

desumanização que é própria desses outros.

Essas ocorrências que desumanizam os linchados, retira-os duplamente da vida social: retira-os como corpos físicos; mas retira-os também simbolicamente, como pessoas, numa espécie de dupla morte, o que fica mais claro nos casos de linchamentos de cadáveres. Para que matar o morto? Porque é preciso matá-lo, também, simbolicamente, matá-lo para a sociedade, matar a possibilidade de sua memória como pessoa. Ao mesmo tempo, elas nos mostram uma sociedade muito diferente da sociedade decorrente de vínculos impessoais e contratuais, que é o que se pressupõe quando se fala de sociedades altamente urbanizadas e modernas. Elas nos revelam que mesmo nos grandes centros urbanos, as pessoas tem uma concepção quase primitiva do que é a sociedade, pois entendem que as relações sociais estão de algum modo sacralizadas pelo pertencimento e pelo sangue. Os linchamentos majoritários que são o do grupo B, o dos moradores e vizinhos, quase que poderiam ser chamados de linchamentos comunitários. As várias modalidades de execução mostram que através do corpo ainda vivo de quem vai ser linchado, reduzido à impotência e a um lento sacrifício, e, depois, através do cadáver do linchado e do uso público que muitas vezes dele se faz, a sociedade se apossa também duplamente do indivíduo: subjugando-o fisicamente e executando-o ritualmente. Mesmo que as pessoas não pareçam ter nenhuma compreensão e nenhuma consciência da maior parte dos símbolos que manipulam nessas ocasiões e dos significados que invocam para efetivar o justiçamento, ainda assim é indiscutível a dimensão ritual dessas ocorrências.

Quando se consideram essas características em relação aos índices do grupo A de linchadores (parentes e vizinhos), eles tendem a ser mais acentuados e mais claramente excludentes. Nesse grupo, 22,8\% dos casos envolvem claras indicações de ritos, em contraposição a apenas 7,8\% nos casos de linchamentos praticados pelo grupo D (multidão). No grupo A há também maior incidência de linchamentos de pessoas que se poderia classificar precariamente como liminares e desprotegidas, como é caso dos índios (legalmente, aliás, menores de idade) e dos doentes mentais: 9,1\%. Enquanto que no grupo D o índice é de 5,4\%.

O cenário de atuação dos grupos difere muito de um para outro. Os linchamentos do grupo D (multidão), em 66,4\% dos casos começam na rua e em $73,3 \%$ terminam na própria rua. Os do grupo A, apenas em 35,7\% dos casos começam na rua e em $48,2 \%$ terminam na rua. Tomando a casa, como cenário simbolicamente próprio do grupo A, é nele que dá início a 18,9\% dos linchamentos e nele conclui apenas 9,6\% das execuções. Já no grupo D apenas $1,5 \%$ dos linchamentos tem início na casa e $0,7 \%$ nela o concluem. É verdade que para ambos a casa está entre os lugares evitados para os linchamentos, com frequiência sendo a pessoa que vai ser linchada removida para a rua. As casas de comércio, especialmente os bares, além das ruas, são cenários importantes de atuação do grupo D. De modo muito esquemático, pode-se dizer que a multidão atua, de preferência, no território do público, enquanto o grupo 
dos parentes e amigos tende a agir no território do privado.

E, finalmente, são também diversas as causas de participação nos linchamentos nesses extremos. Considerei na pesquisa quatro modalidades de crimes que têm motivado a participação das pessoas nos linchamentos: causas fúteis $(9,8 \%)$, crimes contra a pessoa $(47,8 \%)$, crimes contra a pessoa e a propriedade $(15,7 \%)$ e crimes contra a propriedade $(24,4 \%)$. Somando os crimes contra a pessoa e a propriedade, separadamente, aos crimes contra a pessoa e aos crimes contra a propriedade, as diferentes motivações nos diferentes grupos de linchadores ficam evidentes. No grupo A, 82,4\% dos linchamentos foram motivados por crimes contra a pessoa e $21,1 \%$ por crimes contra a propriedade. Esse padrão quase se repete no grupo B, dos moradores e vizinhos: $71,9 \%$ por crimes contra a pessoa e $35,3 \%$ por crimes contra a propriedade. No outro extremo, no grupo D (multidão), 40,3\% dos linchamentos tiveram motivação em crimes contra a pessoa e $56,8 \%$ por crimes contra a propriedade. Acompanhando esta última tendência, mas quase como um grupo transitório, o grupo $\mathrm{C}$ tem $64,3 \%$ dos linchamentos motivados por crimes contra pessoa e $54,8 \%$ por crimes contra a propriedade.

A tendência comunitária e, de certo modo, familística, da maioria dos linchadores tem sua contrapartida nos ataques a delegacias e prisões, de um lado, e aos fóruns, de outro, mais naquelas do que nestes. Nestes últimos, a pequena proporção de casos ocorre quando os linchadores invadem as sessões dos tribunais para seqüestrar e executar os réus. $\mathrm{O}$ grupo $\mathrm{A}$ (parentes e amigos) não tem nenhuma ocorrência de invasão de tribunais, mas é também insignificante esse tipo de episódio na ação do grupo D (multidão). Porém, $26,9 \%$ dos linchamentos do grupo A foram consumados nas próprias prisões, geralmente, invadidas e depredadas, enquanto que apenas $1,5 \%$ dos linchamentos do grupo D (multidão) ocorreram nesses locais. No conjunto dos casos, 70,7\% das invasões de prisões para seqüestro e linchamento de presos foram motivadas pelo fato do preso ter cometido crime contra pessoa (e metade das invasões de tribunais foi feita pelo mesmo motivo), subindo para $89,3 \%$ das invasões quando se agrega os casos que incluem crime contra a propriedade (90,0\% dos casos de invasão de fóruns).

Não estamos apenas em face de formas arcaicas de punição sendo aplicadas em cenários modernos, o que já é um desafio para a interpretação sociológica. Estamos em face de processos sociais próprios de uma situação do que se poderia chamar de urbanização insuficiente e inconclusa. Quando se fala de exclusão, como está em moda nos dias de hoje, deve-se, no meu modo de ver, considerar que ela se materializa na privação de compreensão da lógica própria da vida urbana e civilizada (Foracchi, 1982, p. 11-17). A violência dos linchamentos só pode ser compreendida nessa perspectiva, na medida em que se trata da segunda violência e não da primeira, isto é, trata-se de uma violência-resposta à violência urbana. Nesse sentido, os linchamentos encerram uma crítica prática às instituições e à lei, que se expressa na associação entre o comunitarismo dos grupos de linchadores com o ataque às dele- 
MARTINS, José de Souza. Linchamento, o lado sombrio da mente conservadora. Tempo Social; Rev. Sociol. USP, S. Paulo, 8(2): 11-26, outubro de 1996.

gacias para sequiestrar presos e executá-los. Estamos em face de uma disputa de direito em torno do corpo do criminoso. Na prática, os linchadores dizem que o corpo do criminoso pertence à sua vítima, que fala e age pelas mãos (e também pelos pés) dos grupos de execução. E as polícias, quando se revelam incapazes de assegurar a integridade física dos presos e de entregá-los vivos e íntegros à autoridade judicial para que os julgue e puna de acordo com a lei e as características do crime, também estão, na prática, reconhecendo a sobreposição da justiça popular à justiça pública mediada pelo Estado. Diversamente da justiça institucional, como observou Foucault, na justiça popular "não há três elementos; há as massas e os seus inimigos" (Foucault, 1982, p. 45). Nesse caso, as polícias se negam como instituições públicas e se revelam ambíguas em relação aos arcaísmos que proclamam uma concepção de sociedade reduzida às paixões dos agentes do privado.

$\mathrm{Na}$ medida em que as contradições e desencontros das grandes cidades geram privações e violências que tem como resposta o justiçamento baseado em concepções integristas e comunitárias, o que temos é a insuficiente constituição do urbano como uma de suas causas principais. Não por acaso, os linchamentos ocorrem predominantemente nos bairros de periferia, lugares de migrantes e populações adventícias sem tradição e raízes nas localidades de adoção. A cidade, cada vez mais, recebe, mas não acolhe. Antes, tende a marginalizar. Quando constatamos que os linchamentos se concentram nas áreas metropolitanas e, portanto, nas grandes cidades, não podemos esquecer que se concentram nos setores menos urbanizados e menos ressocializadores para o urbano e moderno. Os cenários principais dos linchamentos não estão nos lugares centrais das áreas metropolitanas, mas nas regiões limítrofes entre favelas e bairros pobres ou de baixa classe média.

A forma como as mudanças sociais são vivenciadas, representadas pela migração e pela inserção marginal no mundo urbano e na economia da grande cidade, traduz essa vivência não só numa permanente consciência de medo, mas também numa permanente consciência de que o novo (a nova situação) é injusto e moralmente intolerável. Os linchamentos, como os saques e os quebra-quebras, são as formas extremas de polarização e expressão dessa consciência e desses sentimentos de privação moral. Essa linha demarcatória das incertezas tanto dos que têm quanto dos que não têm, transforma em linchadores não só os pobres, que se sentem injustiçados e lincham ricos e pobres, mas também os ricos, que se sentem com medo e também lincham, sobretudo nas cidades do interior.

A dinâmica própria dos ajuntamentos e multidões, que faz com que cada indivíduo seja ele mesmo e todos, a um só tempo, fazendo coisas, como linchar, que em outra situação não faria, constitui apenas um dos aspectos dos processos que estão efetivamente envolvidos na crescente prática dos linchamentos. A excludência da injustiça cotidiana para os que sofrem carências e privações já define uma situação de duplo, de estar à margem, de ser membro e não ser, de ter direitos e não ter. Como também vivem a situação de 
MARTINS, José de Souza. Linchamento, o lado sombrio da mente conservadora. Tempo Social; Rev. Sociol. USP, S. Paulo, 8(2): 11-26, outubro de 1996.

${ }^{11}$ Rudé, um especialista em história das multidões, chama a atenção para o fato de que "formas passadas ou 'arcaicas' podem estender-se até o presente", pois, sobretudo nos períodos de transição, esses arcaismos tendem a se constituir numa solução transitória para as demandas sociais, não se confundindo com formas de ação coletiva do passado nem com as modernas formas de ação coletiva (cf. Rudé, 1991, p. 3-5). duplo os que não têm tais carências e, por isso mesmo, carecem de segurança. Nessas diferentes situações vai se definindo uma consciência de vítima potencial do outro (e de quem está "do outro lado") que é a base da incerteza, do medo e do ódio. A situação de multidão materializa a dupla personalidade de seus participantes, de que falaram os clássicos do assunto, ainda que de modos diferentes nos quatro diferentes grupos que foram considerados: nela, o homem da vigília, da lei e da razão, cede lugar ao linchador, que faz justiça pelas próprias mãos, contra todos os princípios da luminosidade transparente e todos os princípios da razão.

A crítica conservadora ao mundo moderno, que seria o mundo da multidão, presente na interpretação leboniana, não tem condições de revelar que o próprio mundo do conservadorismo e das concepções tradicionais ganha uma força patológica evidente nos casos de linchamento. As concepções totalizantes e orgânicas que mediatizam três quartos dos casos de linchamento, que são concepções conservadoras, têm nos linchamentos um desdobramento sombrio. Não só pelos crimes em si que os linchamentos efetivamente são. Mas, sobretudo porque os linchamentos nos revelam que esta sociedade é incapaz de abranger em laços de tipo contratual, na reciprocidade de direitos e deveres, grandes parcelas de sua população: mais de 260 mil brasileiros participaram de linchamentos nas duas últimas décadas. Nesse cenário de urbanização inconclusa, insuficiente, patológica e excludente, de relações sociais essencialmente mediadas por privações, os processos sociais regeneram com facilidade significações arcaicas ${ }^{11}$ que revestem de alguma coerência um modo de vida que, mais do que contraditório e excludente, é carente de sentido. Como vários depoimentos revelam, é o que dá à consciência dos protagonistas da injustiça do linchamento a certeza de que participaram de um ato moralmente justo.

Recebido para publicação em agosto/1996

A pesquisa sobre Linchamentos no Brasil recebe um auxílio da FAPESP - Fundação de Amparo à Pesquisa do Estado de São Paulo e é apoiada pelo CNPQ - Conselho Nacional de Desenvolvimento Científico e Tecnológico com uma bolsa de pesquisa. 
MARTINS, José de Souza. Linchamento, o lado sombrio da mente conservadora. Tempo Social; Rev. Sociol. USP, S. Paulo, 8(2): 11-26, outubro de 1996.

MARTINS, José de Souza. Lynching, the dark side of the conservative mind. Tempo Social; Rev. Sociol. USP, S. Paulo, 8(2): 11-26, october 1996.

ABSTRACT: The various cases of lynching in Brazil in the last 20 years suggest that the social changes are occuring in a direction opposed to the one of social scientists' cognitive orientations. The lynchings point out that popular culture in the circumstances of excluding development and modernization is not always and necessarily concerned with affirming traditions which dignify the man and assert his emancipation and liberty. There is no doubt the lynchings reveal a mentality compromised with the primacy of the social and of the rights of society regarding the individual. But they reveal it in its most opressing and punitive dimension, incorporating violent forms of exclusion and of ritual dehumanization of its victims.

\section{REFERÊNCIASBIBLIOGRÁFCAS}

Andrade, Maristela. (1991) Violência contra crianças camponesas na Amazônia. In: MARTins, José de Souza (coord.). O massacre dos inocentes (a criança sem infância no Brasil). São Paulo, Editora Hucitec.

Beasley, Maurine. (1982) The muckrakers and lynching: a case study in racism. Journalism History, 9 (3-4): 86-91, autumn-winter.

BENEVIDEs, Maria Victoria. (1982) Linchamentos: violência e 'justiça' popular. In: Da MatTA, Roberto et alii. Violência brasileira. São Paulo, Brasiliense.

BLumer, Herbert. (1962) Comportamento coletivo. In: LeE, Alfred McClung (ed.). Princípios de sociologia. Trad. Francisco M. D. Leão et alii. São Paulo, Editora Herder.

Boxer, C. R. (1969) A idade de ouro do Brasil. Trad. Nair Lacerda, 2a edição. São Paulo, Companhia Editora Nacional.

BREED, Warren. (1958) Comparative newspaper handling of the Emmett Till case. Journalism Quarterly, Urbana, 35: 291-298.

Brown, Richard Maxwell. (s.d.) The American vigilant tradition. In: GRAHAM, Hugh Davis \& GurR, Ted Robert (eds.). The history of violence in america. New York, Frederick A. Praeger Publishers.

Canetti, Elias. (1973) Crowds and power. Trad. Carol Stewart. Harmondsworth, Penguin Books.

Diário Popular. (1996) São Paulo, $1^{\circ}$ de março.

ForACCHI, Marialice Mencarini. (1982) A participação social dos excluídos. São Paulo, Editora Hucitec.

Foucault, Michel. (1982) Microfísica do poder. $3^{\text {a }}$ edição. Rio de Janeiro, Edições Graal Ltda.

UNITERIMS:

lynchings,

vigilantism, popular justice, antijudicial justice. 
Goetz, Jill. (1987) Lost in the crowd. Psychology Today, 21, june.

Hollon, W. Eugene. (1974) Frontier violence - another look. New York, Oxford University Press.

LE Bon, Gustave. (1977) The crowd - a study of the popular mind. Harmondsworth, Penguin Books.

Martins, José de Souza. (1989) Linchamentos - a vida por um fio. Travessia, São Paulo, Centro de Estudos Migratórios, Ano II (4): 21-27, maioagosto.

Moisés, José Álvaro \& Martinez-Alier, Verena. (1977) A revolta dos suburbanos ou 'patrão, o trem atrasou'. In: MoIsÉs, José Álvaro et alii. Contradições urbanas e movimentos sociais. Rio de Janeiro/ São Paulo, Paz e Terra/Cedec - Centro de Estudos de Cultura Contemporânea.

. Protesto urbano e política: o quebra-quebra de 1947. In: MoIsÉs, José Álvaro et alii. Cidade, Povo e Poder. Rio de Janeiro/São Paulo, Paz e Terra/Cedec - Centro de Estudos de Cultura Contemporânea.

NunEs, Edison. (1982) Inventário dos quebra-quebras nos trens e ônibus em São Paulo e Rio de Janeiro, 1977-1981. In: MoIsÉs, José Álvaro et alii. Cidade, povo e poder. Rio de Janeiro/São Paulo, Paz e Terra/ Cedec - Centro de Estudos de Cultura Contemporânea.

O Dia. (1996) Rio de Janeiro, $1^{\circ}$ de março.

RudÉ, George. (1991) A multidão na história (estudo dos movimentos populares na França e na Inglaterra, 1730-1848). Trad. Waltensir Dutra. Rio de Janeiro, Editora Campus

Sederberg, Peter C. (1978) The phenomenology of vigilantism in contemporary America: an interpretation. Terrorism, 1(3-4): 287305.

SNYDER, David \& KelLY, William R. (1977) Conflict intensity, media sensivity and the validity of newspaper data. American Sociological Review, 42(1):105-123, February.

VAINFAS, Ronaldo. (1995) A heresia dos índios. São Paulo, Companhia das Letras. 